Article

\title{
Loss and Damage Estimation for Extreme Weather Events: State of the Practice
}

\author{
Charles Doktycz and Mark Abkowitz * \\ Department of Civil \& Environmental Engineering, Vanderbilt University, Nashville, TN 37235, USA \\ * Correspondence: mark.abkowitz@vanderbilt.edu
}

Received: 11 July 2019; Accepted: 2 August 2019; Published: 6 August 2019

\begin{abstract}
Extreme weather, climate-induced events that are episodic (e.g., hurricane, heatwave) or chronic (e.g., sea-level rise, temperature change) in nature, is occurring with increasing frequency and severity. This places a growing and time-sensitive need on the development and implementation of adaptation policies and practices. To motivate adaptive behavior, however, requires the ability to deliver improved risk-informed decision-making capability. At the crux of this challenge is the provision of full and accurate loss and damage accounting of the overall impact of an extreme weather event, enabling the business case to be made for adaptation investment. We define loss and damage as the manifestation of impacts associated with extreme weather that negatively affect human and natural systems. Progress in the development of adequate loss and damage accounting has been hampered by issues, such as discrepancies in conceptual frameworks, problems associated with data quantity and quality, and lack of standardized analysis methodologies. In this paper, we have discussed the conceptual basis for measuring loss and damage, reviewed the state of loss and damage data collection and modeling, and offered a narrative on the future direction of the practice.
\end{abstract}

Keywords: extreme weather; climate change; loss and damage; resilience; risk management; adaptation; natural hazard; business case

\section{Introduction}

Extreme weather events worldwide have been increasing at an alarming rate in terms of both frequency and consequence, creating a compelling need for proactive risk management [1]. While improved disaster reporting may serve as a partial explanation of this observed trend, it does not explain the temporal and spatial impacts that are being realized [2].

The 2018 Intergovernmental Panel on Climate Change report heralded the need to accelerate global climate change adaptation [3], stating with high confidence that human activities have caused approximately $1.0^{\circ} \mathrm{C}$ of global warming, and we are on pace to reach $1.5^{\circ} \mathrm{C}$ in the coming decades. The consequences of this forecast are that trends in intensity and frequency of weather extremes are likely to persist for the foreseeable future. Although some climate change adaptation measures are being undertaken, these efforts must be expanded and implemented more rapidly than previously anticipated.

At the crux of improving risk-informed decision-making and motivating adaptive behavior, is making the business case for investing in such policies and practices. The concept of a business case involves a full accounting of the cost of investing in a risk mitigation strategy compared to the derived benefits, creating an ability to determine if the return-on-investment warrants expenditure of resources. In the case of extreme weather, the benefits accrue in the form of cost avoidance; that is, expenditures that do not have to be incurred due to strategy implementation having mitigated the severity of the impacts. A complete assessment of cost avoidance requires a comprehensive approach to loss and damage accounting, both in terms of accuracy, completeness, and uniformity. 
The United Nations Framework Convention on Climate Change defines loss and damage as "the actual and/or potential manifestation of impacts associated with climate change in developing countries that negatively affect human and natural systems" [4]. While there is no question that developing countries are a key focal point of the conversation, this definition and the need for loss and damage assessment applies to first world countries as well.

Unfortunately, to date, the lack of standardized and comprehensive methods for loss and damage data collection, analysis, and reporting has posed challenges. In this paper, we discussed the conceptual basis for measuring loss and damage, reviewed the state of loss and damage data collection and modeling, and offered a narrative on the future direction of the practice. In the following discourse, we have used the term "extreme weather" as including both episodic (e.g., flood, wildfire) and chronic (e.g., sea-level rise, temperature change) events, both of which are climate-induced.

\section{Conceptual Framework for Loss and Damage Estimation}

Loss is commonly defined as the negative impacts in which restoration or reparation is impossible [5,6], whereas damage is considered those negative impacts for which restoration or reparation is possible. The estimation of loss and damage is typically approached categorically, generally separated into the tangible and intangible cost [5,7]. Tangible loss and damage can be further sub-divided into direct and indirect impacts. Some studies define risk mitigation as a category, as well.

\subsection{Direct Tangible Costs}

Direct tangible costs are considered those that occur as a direct result of the physical impact of the event [8]. Common examples include damage to infrastructure and property loss (e.g., cars, livestock, crops). Fatalities and injuries may appear in this category or be included elsewhere, depending on whether the cost of human harm is considered a tangible or intangible cost due to the complexity in the quantification of the value of human life.

Direct cost measurement is most frequently performed using damage functions, which describe the relationship between a hazard parameter and the resulting monetary cost (e.g., cost per square foot of residential housing). Some models account for resistance parameters, such as building type or a risk mitigation measure that has been implemented [7]. Market price methods are popular in assessing direct tangible costs, as these valuation techniques reflect current replacement costs, are easy to apply, and applicable to many economic sectors.

Direct cost estimation can be limited by the quality and quantity of available data, however, which can vary widely depending on the location of the event and the information source. Such inconsistencies, inaccuracies, and missing data contribute to greater estimation uncertainty, leading many analysts to utilize cost ranges rather than specific values. Additionally, complexities in understanding the process leading to loss and damage often result in the use of multi-parameter models that require the introduction of additional variables, causing further uncertainty in the estimation process.

\subsection{Indirect Tangible Costs}

Indirect tangible costs are generally considered as those that occur as a result of a direct impact [8]. Examples include business interruption, relief efforts, lost tourism, relocation costs, disruption to transportation, and diminished living conditions.

Common approaches to indirect cost estimation include the use of surveys, econometric models, input/output models, and computable general equilibrium analysis (CGE) models [7]. Surveys are often narrow in scope, and consequently, the applicability of the results can be limited. Econometric models provide an opportunity for broader application, and the results can be used in future forecasts. Input-output models contain coefficients to estimate impacts that an initial change in economic activity has on a regional economy, where the initial change and coefficients are determined based on extreme weather event severity [9]. Note, however, that input-output models require assumptions in economic behavior with the potential to bias the magnitude of the results [7]. CGE models, while based on the 
input-output structure, place greater emphasis on price, with substitution options not included. As a result, CGE models often result in lower loss estimates than input-output models. However, CGE models assume markets function perfectly post-disaster, which is rarely the case.

\subsection{Intangible Costs}

Intangible costs are effects felt by society, but for which the accompanying loss and damage are difficult to value monetarily. Examples include environmental, educational, cultural, and health/well-being impacts. Depending on the assessment framework, human harm can be placed in this category as well. Intangible costs are typically difficult to quantify because of the subjective nature of the variables involved, as putting a dollar value on impacts, such as environmental degradation or cancer risk, is a complex process that can include several considerations.

One approach to quantifying loss and damage is through the use of revealed preference and stated preference methods [10]. Revealed preference methods produce estimates of the value of a particular good or service from actual market behavior. Types of revealed preference methods include hedonic pricing, travel cost, cost of illness, and replacement cost. Stated preference methods create a hypothetical or contingent market for choice analysis; methods include contingent valuation, choice modeling, and life satisfaction analysis. Whereas revealed preferences look towards related markets, where the non-market good is implicitly traded, stated preference methods take a survey-based approach that considers an individual's preference directly by determining a willingness to pay or a willingness to accept. Regardless of the approach, however, the resulting estimated value for intangible damages is not equivalent to a market price, which is the monetary standard for comparison [11].

\subsection{Risk Mitigation Costs}

Risk mitigation costs represent the investment that is made to achieve a reduction in loss and damage when an extreme weather event is experienced. As such, it is considered as a cost incurred against which to compare the cost reductions in unrealized loss and damage. It is on this basis that the benefit/cost of a candidate risk mitigation strategy can be evaluated, with the ultimate goal of determining whether such an investment is warranted. Common risk mitigation costs include investments made for [12]: (1) management practices, (2) land-use planning, (3) hazard modification, (4) infrastructure adaptation, (5) communication in advance of events, (6) emergency response and evacuation, (7) financial incentives, and (8) risk transfer (e.g., insurance). Risk mitigation costs are relatively easy to quantify and can be determined by the available market price for the cost of implementation [7].

\section{Loss and Damage Data}

In utilizing databases for loss and damage estimation, one must be mindful of several potential biases that might be present, including [13]:

- Hazard bias—over or under-representation of certain hazard types due to selective reporting.

- Temporal bias-loss and damage, exhibiting an upward trend over time as a result of increased wealth and population sizes, or perhaps improved accounting.

- Threshold bias-inconsistent inclusion criteria across databases, creating discrepancies.

- Accounting bias-inconsistencies in how loss and damage are accounted for due to the variety of input methods used.

- Geographic bias-changes in political geography, creating spatial inconsistencies in loss and damage accounting.

- Systemic bias-between and within loss and damage reporting, arising from computational inconsistencies (e.g., reporting in dollar losses at the time of occurrence vs. inflation-adjusted losses). 
- Measurement bias—-the use of different metrics to measure loss and damage, making it difficult to normalize.

While several approaches to loss and damage estimation have emerged, each embodying a unique set of cost categories and input variables, the databases they generally rely upon are limited to information made available by a small number of sources. Here, we have reviewed the most popular: (1) EM-DAT (Emergency Events Database), (2) NatCatSERVICE, (3) Sigma CatNet, and (4) SHELDUS (Spatial Hazard Events and Losses Database for the United States).

\subsection{Emergency Events Database (EM-DAT)}

EM-DAT is a publicly accessible, international database of global natural and technological disasters, maintained by the Centre for Research on the Epidemiology of Disasters [14]. It is intended to provide an objective basis for vulnerability assessment and decision-making by collecting, organizing, and providing access to validated data on the human impact of disasters and disaster-related economic damage estimates. The database consists of approximately 19,000 entries, covering from the calendar year 1900 to present. Natural disasters are divided into six groups (geophysical, meteorological, hydrological, climatological, biological, and extraterrestrial), covering 15 disaster types and over 30 sub-types. Technological disasters are divided into three groups (industrial, transport, and miscellaneous), covering 15 disaster types (see Table 1). Data sources include governments, United Nations (UN) agencies; United Nations Environment Program (UNEP), United Nations Office for the Coordination of Humanitarian Affairs (UNOCHA), World Food Program(WFP), Food and Agriculture Organization (FAO), and other non-governmental organizations; research institutions, insurance companies, and media reports.

Table 1. EM-DAT Disaster Classifications.

\begin{tabular}{|c|c|c|c|c|c|c|c|c|}
\hline Geophysical & Meteorological & Hydrological & Climatological & Biological & Extraterrestrial & Industrial & Transport & Misc. \\
\hline Earthquake & $\begin{array}{c}\text { Extreme } \\
\text { temperature }\end{array}$ & Flood & Drought & Epidemic & Impact & $\begin{array}{l}\text { Chemical } \\
\text { spill }\end{array}$ & Air & Collapse \\
\hline \multirow{2}{*}{$\begin{array}{c}\text { Dry mass } \\
\text { movement } \\
\text { Volcanic } \\
\text { activity }\end{array}$} & Storm & Wave action & Wildfire & Animal & & Explosion & Rail & Fire \\
\hline & & & & & & $\begin{array}{c}\text { Fire } \\
\text { Gas leak } \\
\text { Poisoning } \\
\text { Radiation } \\
\text { Oil spill } \\
\text { Other }\end{array}$ & Water & Other \\
\hline
\end{tabular}

Criteria for database inclusion are events in which there are at least ten fatalities, at least one hundred people affected, declaration of a state of emergency, and/or a call for international assistance. Events are entered on a country-level basis, with attributes consisting of location; date; number of people killed/injured/missing; number of people homeless/affected; economic loss, both direct (e.g., damage to infrastructure, crops, housing) and indirect (e.g., loss of revenues, unemployment, market destabilization); international aid contributions; composite indicators (total affected and victims). The disaster classification used in EM-DAT is adapted from Integrated Research on Disaster Risk (IRDR) Peril Classifications [15].

EM-DAT data entry guidelines follow three levels. Level 1 includes information regarding the disaster event, including the group, sub-group, and disaster type, sub-type, and sub-sub-type. The second level consists of geographic and temporal information, physical characteristics, and status. Spatial divisions specifying the continent, country, region, latitude/longitude of the disaster, a three-letter International Organization for Standardization (ISO) code, and temporal information (start/end dates and local time) are reported. Physical characteristics of the event include origin, associated disasters, and scale/intensity (reported in units linked to the disaster type, such as the area 
covered in wildfire reports and the Richter scale for earthquake events). Status reporting lists aid contributions (total amount given in USD current value), Office of U.S. Foreign Disaster Assistance (OFDA) response, date of appeal for international assistance, and if a declaration of emergency was made. Level 3 consists of the source of information along with a reliability score for the source, between one (low) and five (high). Level 3 also includes the human impact of the event, in terms of deaths, missing, homeless, injured, and affected people requiring immediate assistance during an emergency. The economic impact is reported in Level 3, which includes total estimated damages, reconstruction costs, insured losses, and the disaster impact. Total damage costs are defined as the value of all damages and economic losses directly or indirectly related to the disaster, which may be segmented by sector: social, infrastructure, production, environment, and other. Reconstruction costs are the costs for replacement of lost assets, while insured losses are the economic damages covered by insurance. The disaster impact report category specifies the sectors affected by the disaster, which include animals, electricity, water supply and sanitation, communications, cultural infrastructure, and others. Infrastructure reports include a percentage of damage of destruction to certain infrastructure and number of affected houses, bridges, businesses, and schools.

\subsection{NatCatSERVICE}

NatCatSERVICE is a comprehensive global natural hazard catastrophe database maintained by Munich RE, containing records dating back to 1980, and retrospectively all great disasters since 1950 (see Table 2). Catastrophe events include those classified as geophysical (earthquake, volcano, dry mass movements), meteorological (storms), hydrological (flooding, wet mass movements), and climatological (extreme temperature, drought, wildfire). Data is made available through an online tool where the user can designate the period of interest (years), location (continent), and the event type [16]. The loss event classification in NatCatSERVICE is closely related to the IRDR Peril classifications (also adopted by EM-DAT), defined by an overarching family of events, and sub-perils that more closely describe the physical forces behind the event.

Table 2. NatCatSERVICE Hazard Categories.

\begin{tabular}{cccc}
\hline Geophysical & Meteorological & Hydrological & Climatological \\
\hline Earthquake & Storm & Flooding & Extreme temperature \\
\hline Volcano & & Wet mass movements & Drought \\
\hline Dry mass movements & & & Wildfire \\
\hline
\end{tabular}

Events are rated on the following scale: 0 -no fatalities and no property damage, $1-$ small-scale property and structural damage and between 1-9 fatalities, 2-moderate damage and greater than 10 fatalities, 3-damage in excess of $\$ 60$ million plus greater than 20 fatalities, 4-damage in excess of $\$ 250$ million with over 100 fatalities, 5-damage in excess of $\$ 650$ million and over 500 fatalities, and 6- "great disaster" where a region's ability to help itself is overtaxed, and international assistance is necessary, thousands of fatalities and just as many without homes, major economic losses, and insured losses reaching exceptional orders of magnitude. Each record in the database is characterized by the following attributes: date; event type; geocoding of main loss areas; nature of the event; loss data (insured losses, overall losses, bodily injuries), infrastructure areas; affected industries; event description (e.g., wind strength, precipitation levels, earthquake magnitude).

The database gathers information from a wide range of sources, using data mining and surveys among internet portals, institutions, direct contacts, and specialized companies. Any contradictory information is assessed internally. Events listed in the database have an assigned direct economic loss measured in USD. Due to potential variability in reporting accuracy and consistency, NatCatSERVICE defines five levels of loss estimates, ranging from full information to partial data or only event descriptions. Each level utilizes a separate approach for damage estimation, with loss estimates based 
on insurance market data offering the highest quality of reporting. In low-quality information cases, asset value assumptions are utilized, based on home value repair costs for listed damaged assets, with further assumptions made for infrastructure and agriculture sectors.

Loss and damage analysis can be performed according to (1) country mortality rates (high, upper-middle, lower-middle, and low), (2) insurance penetration (high, middle, low, very low), and (3) income group (high, upper-middle, lower-middle, and low). The products offered by NatCatSERVICE include an analysis of the number of events, as well as overall loss/insured loss ratio, which can be tracked by inflation-adjusted and normalized overall losses. The tool also provides a breakdown of the percentage distribution for relevant natural loss events worldwide as well as a map showing where each event occurred [17].

\subsection{Sigma CatNet}

Sigma CatNet, maintained by Swiss RE, a global reinsurer headquartered in Zurich, Switzerland, consists of a limited access global disaster database containing both manmade and natural catastrophes [18]. The database includes events from 1970 to present, and requires one of the following to have occurred in order to be included: (1) 20 or more deaths and/or people missing, (2) 50 or more people injured, (3) 2000 or more people left homeless, (4) insured losses of greater than $\$ 17.9$ million (marine), (5) insured losses of greater than $\$ 35.8$ million (aviation), (6) insured losses of greater than $\$ 44.5$ million (all other losses), or (7) total losses in excess of $\$ 88.9$ million (see Table 3). This information is obtained through internal research performed by Swiss RE, natural disaster coordination agency research data, publicly released information, and press, industry, and aid agency reports [14]. Minimal discussion is provided, however, regarding validation of the database sources.

Table 3. CatNet Event Categories.

\begin{tabular}{llll}
\hline \multicolumn{1}{c}{ Flood } & Earthquake and Tsunami & \multicolumn{1}{c}{ Storm } & Other \\
\hline River flood & Seismic hazard & Wind speed & Lightning \\
\hline Coastal flood & Epicenters & Tropical cyclone tracks & Volcanoes \\
\hline Dyke ring projection & Plate boundaries & Hailstorms & Volcano ash thickness \\
\hline Historic floods & Tsunami historical run-up & Tornado & Wildfire \\
\hline & Tsunami hazard & $\begin{array}{l}\text { Historic tropical } \\
\text { cyclones }\end{array}$ & Climate change \\
\hline & Historic earthquakes & Historic winter storms & Climate data \\
\hline
\end{tabular}

Attributes for each record include fatalities, injuries, missing persons, homeless (unable to occupy their dwelling), and economic losses (direct/indirect/insured). Although some indirect economic loss is represented, such as business interruption, other such loses are not considered (e.g., loss of earnings by suppliers due to disabled businesses, estimated shortfalls in Gross Domestic Product, non-economic losses). Swiss RE cautions that total losses represent general estimates that are communicated in different ways, such that the data should not be used to perform direct comparisons between events.

\subsection{SHELDUS}

The Spatial Hazard Events and Losses Database for the United States (SHELDUS) records natural hazard events at the county level, covering the entire U.S., except U.S. territories [13]. SHELDUS is maintained by the Center for Emergency Management and Homeland Security at Arizona State University. The database covers events from 1960 to present and includes 18 natural hazard event types (see Table 4), populated with attributes describing the date, location, and direct losses (property, crop, injuries, fatalities). The database can also be searched by specific peril, from among 139 different peril types. 
Table 4. SHELDUS Event Categories.

\begin{tabular}{cccc}
\hline Geophysical & Meteorological & Hydrological & Climatological \\
\hline Avalanche & Fog & Flood & Drought \\
\hline Coastal & Hail & Tsunami/Seiche & Wildfire \\
\hline Earthquake & Heat & \\
\hline Landslide & Hurricane/Tropical storm \\
\hline Volcano & Lightning \\
\hline Severe storm \\
\hline Tornado \\
\hline Wind \\
\hline
\end{tabular}

Most of the SHELDUS data is sourced from the National Weather Service (NWS), including the NWS process for loss estimation, including how to determine direct and indirect fatalities and injuries associated with the event. Loss estimates are recorded as actual dollar amounts if a reasonably accurate estimate is considered available. Otherwise, either an estimate is attempted or "no information available" is entered (except for flooding events, where an estimate is required by the U.S. Army Corps of Engineers). In cases where estimates are reported as ranges rather than specific values, SHELDUS enters the lower bound of the range in the database. If events are reported for regions rather than specific counties, the impacts are distributed equally across the involved counties, which often results in non-integer fatality and injury entries.

\subsection{Further Discussion}

Table 5 presents a comparative summary of the characteristics of the aforementioned databases. As noted, each database covers a different period, geography, hazard definition, and sources of information.

From the standpoint of attempting to estimate loss and damage at the local level, SHELDUS is best suited for that purpose [19]. This database, although limited to the United States, provides records at the county level, the most disaggregate geographic delineation among the group, and has a lower reporting threshold such that more event information is available. Although SHELDUS also provides the most readily available loss information for analysis, even its data records are incomplete, as they do not contain any information associated with indirect or intangible loss and damage.

When considering global or national disaster trends, use of EM-DAT, CatNet, or NatCatSERVICE is more desirable, given their worldwide coverage and reporting at a more aggregate scale. In each of these cases, the reporting threshold is such that only the more catastrophic events are captured, and not the entire distribution of impactful events. Moreover, none of these databases afford complete coverage of direct, indirect, and intangible impacts. Also of note, only EM-DAT and SHELDUS provide an opportunity to download raw data for analysis use, whereas CatNet and NatCatService only allow viewing privileges, functioning more like an interactive online tool with a supporting database.

The bottom line is that there is a paucity of available extreme weather loss and damage data at a time when there is a compelling need to have access to such information. This creates a major gap in having the ability to make the business case for adaptation investment. 
Table 5. Comparison of Loss and Damage Databases. (Adopted from Integrated Research on Disaster Risk (IRDR) Peril Classification and Hazard Glossary (IRDR, 2014) [15]).

\begin{tabular}{|c|c|c|c|c|}
\hline & EM-DAT & SHELDUS & NatCatSERVICE & Sigma CatNet \\
\hline Total records & $>20,000$ & $>800,000$ & $>33,000$ & $>9000$ \\
\hline Record span & 1900-Present & 1960-Present & 1980-Present & 1970-Present \\
\hline Loss categories & $\begin{array}{l}\text { Fatalities, injuries, homeless/affected, } \\
\text { damage (crop, property, livestock) }\end{array}$ & $\begin{array}{l}\text { Direct property damage, crop } \\
\text { damage, injuries, fatalities }\end{array}$ & $\begin{array}{l}\text { Direct economic loss estimates, insured } \\
\text { losses, fatalities }\end{array}$ & $\begin{array}{c}\text { Fatalities, missing, victims } \\
\text { (casualties), injured, homeless } \\
\text { (unable to occupy their dwelling), } \\
\text { and economic losses } \\
\text { (direct/indirect/insured) }\end{array}$ \\
\hline Spatial coverage & Global & United States (county level) & Global & Global \\
\hline Source & $\begin{array}{c}\text { https: } \\
\text { //www.emdat.be/explanatory-notes }\end{array}$ & $\begin{array}{l}\text { http://hvri.geog.sc.edu/SHELDUS/ } \\
\text { docs/SHELDUS_ReadMe.pdf }\end{array}$ & $\begin{array}{l}\text { https://www.munichre.com/en/reinsurance/ } \\
\text { business/non-life/natcatservice/index.html }\end{array}$ & $\begin{array}{l}\text { http://www.sigma-explorer.com/ } \\
\text { documentation/Methodology_ } \\
\text { sigma-explorer.com.pdf }\end{array}$ \\
\hline
\end{tabular}




\section{Loss and Damage Methodologies and Frameworks}

Several efforts have been made to incorporate loss and damage estimation, either pre-disaster or post-disaster methodologies [20]. Below, we have reviewed a representative sample of these applications.

\subsection{HAZUS-MH}

Developed by the Federal Emergency Management Agency, HAZUS-MH is a tool for assessing loss and damage associated with hurricane, flood, and earthquake events [21]. It utilizes geographic information systems to estimate hazard-related impacts before or after a disaster. The methodology accounts for loss and damage according to four categories: (1) direct damage, (2) induced damage, (3) direct losses, and (4) indirect losses. Direct damage includes general building stock, essential facilities, and lifelines. Induced damages comprise those caused by fire, hazardous material exposure, and debris generation. Direct losses include the cost of repair/replacement, income loss, crop damage, casualties, shelter, and recovery needs. Indirect losses consist of supply shortages, sales decline, opportunity costs, and economic loss. HAZUS-MH also includes demographic data in its impact reports, including age, sex, income, and household characteristics.

HAZUS-MH is purported to be a comprehensive tool for loss and damage assessment in addressing a couple of extreme weather event types (i.e., flood, hurricane), and is the nationally recommended tool for flood mitigation planning at the county level. However, a recent study calls into question the accuracy of the tool's flood model impact assessment. Key study findings include that HAZUS-MH: (1) underestimates the flood extent boundaries for study regions along major rivers, such as the Mississippi, (2) may be incorrectly predicting the number and location of damaged buildings, and (3) essential facility inventory data underrepresents the accessibility and response capabilities of essential facilities [22].

\subsection{Damage and Loss Assessment (DaLA)}

DaLA was developed by the United Nations Economic Commission for Latin America [23], as an approach to damage and loss assessment, where the onus is on the user to obtain the necessary data for implementation. The methodology focuses on assessing the social, economic, and environmental effects of disasters, separated into direct damage, indirect loss, and macroeconomic effects (i.e., repercussions of direct and indirect damage/loss, measured in terms of how the disaster modifies the performance of main economic variables of the affected country, provided that national authorities make no adjustments). A "reasonable" time frame for assessing macroeconomic effects is defined as the remainder of the year in which the disaster occurs plus up to two additional years; under exceptional circumstances, a five-year accounting can be used.

DaLA defines cost types (direct, indirect, business interruption, intangible, and risk mitigation), and how they can be quantified in monetary terms. The cost of human harm is considered a direct cost, and a suggested monetization is to estimate the future income that the deceased would have generated while fulfilling the individual's average life expectancy. An alternative approach is to value the loss of life as the amount paid by insurance companies based on airline-related accidents from the Warsaw Convention of the International Civil Aviation Organization, but can be problematic due to regional variance. A final proposal for valuing human life is to base it off the amount an individual is willing to pay to avoid premature death.

Indirect costs are defined as the flow of goods and services that will not be produced or rendered after the event and may extend throughout the rehabilitation and reconstruction periods. It is recognized that some indirect effects may have a net positive effect, such as a heightened need for a specific service or product (e.g., generators, building supplies), which should be deducted from the total cost estimate. 
DaLA associates intangible costs with human suffering, insecurity, and impacts on quality of life. While the methodology recognizes the difficulty in placing a monetary value in evaluating these costs, DaLA acknowledges that a complete loss and damage assessment must include these considerations.

\subsection{Post Disaster Needs Assessment (PDNA)}

The goal of the PDNA methodology is to provide support for emergency and recovery management [24]. It embraces the ECLAC method for assessing loss and damage.

The PDNA methodology includes the collection of pre-disaster baseline data for comparison with post-disaster conditions to determine the overall impact and impacts by sector. The assessment includes: (1) damage to infrastructure and physical assets, (2) disruption of access to goods and services, (3) governance and decision-making processes, and (4) increased risks and vulnerabilities. These effects are expressed in both quantitative and qualitative terms, with loss and damage estimation calculated as the value of total and partial destruction of infrastructure and assets, changes in service delivery, production of and access to goods and services, changes to government processes, and changes to risk.

Impact estimation is determined through the economic impact at macro and micro levels, considering likely effects of the disaster on economic performance and macro-economic imbalances, along with impacts on personal household incomes and employment in all sectors. This includes the extent of change in the quality of human life over both medium- and long-term time scales.

Economic loss is defined as the change in economic flow arising from the disaster until full economic recovery and reconstruction are achieved. This includes the decline in output of impacted sectors due to damage to infrastructure and assets, lower revenues associated with demand reduction due to the disaster, and increased expenditure for management of new risks brought on from the disaster. Macro-economic impacts are measured from the post-disaster performance of the gross domestic product, the balance of payments (an increase of imports, a decrease of exports), and the financial sector (increased operational costs). Human development impacts can be measured in terms of the human development index (HDI), hybrid HDI, inequality-adjusted HDI, multi-dimensional poverty index, and gender inequality index. The decision of which indicator(s) to include is generally governed by what is utilized in establishing pre-disaster baseline information.

\subsection{CATSIM (Catastrophe Simulation)}

A simulation model developed by the International Institute for Applied Systems Analysis (IIASA), CATSIM is designed to assess disaster risks in a certain country or region. The methodology is intended to help with natural disaster risk mitigation planning by examining fiscal and economic risk and evaluating the benefits and costs of various risk reduction strategies. CATSIM is an interactive tool, which allows for testing of assumptions through the variation of multiple parameters. The model uses a Monte Carlo simulation of disaster risks in a specified region to derive an estimate of the region's financial vulnerability to the disaster [20]. The methodology is segmented into five modules: (1) risk of direct asset losses, determined through loss distributions and probability loss curves, (2) financial and economic resilience for disaster response, measured through the financing gap concept, (3) financial vulnerability, determined by the risk and financial resilience of the government, (4) economic impacts and resource shortfall consequences, and (5) adaptation/risk management [25]. The model can be utilized at the ex-ante stage, where budget allocation is determined to make natural disaster mitigation decisions, purchase insurance or other protection of assets, or at the ex-post stage, after a disaster in guiding a repair and financial decisions. CATSIM has been used by the World Bank to estimate disaster risk in over 80 countries [26].

\subsection{Further Discussion}

It is commendable that in the evolution of loss and damage frameworks and models, attempts are being made to structure a means to quantify the full impact of natural hazard disaster events. HAZUS-MH represents an all-in-one approach whereby the data and model are integrated within 
the tool, yet it is limited in its representation of extreme weather events, and the validity of the corresponding impact estimation results have been brought into question. The remaining modeling frameworks included in this review are indicative of idealized ways to capture the full range of disaster impacts, including recognition that post-disaster impacts are experienced over an extended period, which can have economic and human development impacts incurred locally and across broader spatial and jurisdictional boundaries. Data necessary to serve as inputs to populate these considerations are generally lacking, however, rendering a barrier to performing full loss and damage accounting that has yet to be overcome.

\section{Conclusions}

There is a clear need to make the business case for investments in extreme weather risk mitigation, making it imperative to perform full loss and damage accounting in evaluating the benefits and costs of various adaptation strategies. Based on our review, we found that the quality of available data and inconsistencies in loss and damage accounting methodology constrain the ability to achieve this objective. Arguably most challenging among these concerns is the difficulty in estimating intangible costs, to the point that the majority of the existing databases and models avoid its consideration altogether. This is unfortunate, given the broad impact and lengthy-time spans, that such impacts can be experienced, such that its magnitude may dwarf the impacts that are currently taken into consideration. To the extent this is the case, the benefits of adaptation strategies may be severely underestimated, biasing the efficacy of attracting investment.

Addressing these needs will require a comprehensive effort to evaluate the full loss and damage impact of disaster events, beginning with the development of use cases based on past events where the process of full recovery has been achieved. This will provide insight into quantifying overall loss and damage, the portion attributed to direct, indirect, and intangible effects, and how it is distributed temporally and spatially. Concurrently, the insurance industry should be encouraged to partner with the public and private sector to produce a methodology and practical approach to measuring loss and damage. Doing so would prove beneficial to all involved parties, as each has a vested interest in better understanding the bottom line.

While attention needs to be focused on improving extreme weather loss and damage accounting, we must also recognize that decision-makers are facing the harsh realities of extreme weather today that require immediate attention. Thus, in helping the practitioner make more risk-informed resource investment decisions in the meantime, we must straddle the fence of not requiring an overabundance of technical requirements while also effectively using available data. To that end, relying on a hybrid of quantitative and qualitative understanding of extreme weather trends may be an appropriate recourse. This particularly applies to situations where adaptation strategies are being evaluated at the screening level, or where local authorities require a simple, practical framework (and one that does not require much training or technical understanding to use) for making more risk-informed decisions given limited time and resources.

Author Contributions: C.D. performed the literature review and conceptualization of this effort. C.D. and M.A. jointly shared in the writing, review and editing of the manuscript.

Funding: Portions of this work were supported by grants from the U.S. Housing and Urban Development to the Tennessee Department of Economic and Community Development in response to the National Disaster Resilience Competition; from the U.S. Department of Transportation, University Transportation Centers Program, administered through the Maritime Research and Education Center (MarTREC), hosted by the University of Arkansas; and from the Dwight David Eisenhower Transportation Fellowship Program.

Conflicts of Interest: The authors declare no conflict of interest.

\section{References}

1. International Council for Science. A Science Plan for Integrated Research on Disaster Risk: Addressing the Challenge of Natural and Human-Induced Environmental Hazards; International Council for Science: Paris, France, 2008. 
2. United Nations International Strategy for Disaster Reduction (UNISDR). Global Assessment Report on Disaster Risk Reduction: Risk and Poverty in a Changing Climate; UNISDR: Geneva, Switzerland, 2009.

3. IPCC. Summary for Policymakers, Global Warming of $1.5^{\circ} \mathrm{C}$-IPCC Special Report on the Impacts of Global Warming of $1.5^{\circ} \mathrm{C}$ above Pre-Industrial Levels and Related Global Greenhouse Gas Emission Pathways; IPCC: Geneva, Switzerland, 2018; p. 32.

4. United Nations Framework Convention on Climate Change. A Literature Review on the Topics in the Context of Thematic Area 2 of the Work Programme on Loss and Damage: A Range of Approaches to Address Loss and Damage Associated with the Adverse Effects of Climate Change: Note; UN: New York, NY, USA, 2012.

5. Gall, M. The suitability of disaster loss databases to measure loss and damage from climate change. Int. J. Glob. Warm. 2015, 8, 170-190. [CrossRef]

6. Andrei, S.; Rabbani, G.; Khan, H.I.; Haque, M.; Ali, D.E. Non-Economic Loss and Damage Caused by Climatic Stressors in Selected Coastal Districts of Bangladesh; Report for the Asian Development Bank; Asian Development Bank: Mandaluyong, Phillipines, 2015.

7. Meyer, V.; Becker, N.; Markantonis, V.; Schwarze, R.; Van Den Bergh, J.; Bouwer, L.; Bubeck, P.; Ciavola, P.; Genovese, E.; Green, C.H.; et al. Assessing the costs of natural hazards-state of the art and knowledge gaps. Nat. Hazards Earth Syst. Sci. 2013, 13, 1351-1373. [CrossRef]

8. Kreibich, H.; Van Den Bergh, J.C.; Bouwer, L.M.; Bubeck, P.; Ciavola, P.; Green, C.; Hallegatte, S.; Logar, I.; Meyer, V.; Schwarze, R.; et al. Costing natural hazards. Nat. Clim. Chang. 2014, 4, 303. [CrossRef]

9. Bess, R.; Ambargis, Z.O. Input-output models for impact analysis: Suggestions for practitioners using RIMS II multipliers. In Proceedings of the 50th Southern Regional Science Association Conference, New Orleans, LA, USA, 24-26 March 2011; Southern Regional Science Association: Morgantown, WV, USA, 2011.

10. Markantonis, V.; Meyer, V. Valuating the intangible effects of natural hazards: A review and evaluation of the cost-assessment methods. In Proceedings of the European Society for Ecological Economics Conference, Istanbul, Turkey, 14-17 June 2011.

11. Morrissey, J.; Oliver-Smith, A. Perspectives on Non-Economic Loss and Damage: Understanding Values at Risk from Climate Change; Loss and Damage Series; United Nations University Institute for Environment and Human Security: Bonn, Germany, 2013.

12. Bouwer, L.M.; Papyrakis, E.; Poussin, J.; Pfurtscheller, C.; Thieken, A.H. The costing of measures for natural hazard mitigation in Europe. Nat. Hazards Rev. 2013, 15, 04014010. [CrossRef]

13. Gall, M.; Borden, K.A.; Cutter, S.L. When do losses count? Six fallacies of natural hazards loss data. Bull. Am. Meteorol. Soc. 2009, 90, 799-810. [CrossRef]

14. Centre for Research on the Epidemiology of Disasters (CRED). Emergency Events Database (EM-DAT). Available online: https://www.emdat.be (accessed on 3 August 2019).

15. Integrated Research on Disaster Risk. Peril Classification and Hazard Glossary; IRDR DATA Publication; Integrated Research on Disaster Risk: Beijing, China, 2014; No. 1.

16. Munich RE. Available online: https://natcatservice.munichre.com/ (accessed on 3 August 2019).

17. Monti, A.; Tagliapietra, C. Tracking insurance industry exposures to CAT risks and quantifying insured and economic losses in the aftermath of disaster events: A comparative survey. In Proceedings of the 2nd Conference on the Financial Management of Large-Scale Catastrophes, Bangkok, Thailand, 24-25 September 2009.

18. Swiss RE. Available online: https://www.swissre.com/reinsurance/property-and-casualty/solutions/propertyspecialty-solutions/catnet.html (accessed on 3 August 2019).

19. Gall, M.; Emrich, C.; Cutter, S. Who Needs Loss Data? Technical Report; UNISDER: Geneva, Switzerland. [CrossRef]

20. Surminski, S.; Lopez, A.; Birkmann, J.; Welle, T. Current knowledge on relevant methodologies and data requirements as well as lessons learned and gaps identified at different levels, in assessing the risk of loss and damage associated with the adverse effects of climate change. In Assessing the Risk of Loss and Damage Associated with the Adverse Effects of Climate Change; UNFCCC: Bonn, Germany, 2012.

21. Federal Emergency Management Agency. Multi-Hazard Models. Available online: https://www.fema.gov/ multi-hazard-models (accessed on 3 August 2019).

22. Abkowitz, M.; Camp, J.; Gillespie-Marthaler, L.; Allen, M. Development and Implementation of Sustainable Transportation Resilience Indicators. Zenodo 2019. [CrossRef] 
23. ECLAC. Handbook for Estimating the Socio-Economic and Environmental Effects of Disasters; LC/MEX/G.5. LC/L.1874; UN-ECLAC: Santiago, Chile, 2003.

24. World Bank. Post-Disaster Needs Assessment Guidelines; World Bank Group: Washington, DC, USA, 2013; Volume A.

25. Hochrainer-Stigler, S. User Interface of the CatSim Model and Practical Guidelines; IIASA: Laxenburg, Austria, 2014; pp. 1-17.

26. Mechler, R. CATSIM. Available online: www.iiasa.ac.at/web/home/research/researchPrograms/RISK/CATSIM. en.html (accessed on 3 August 2019).

(C) 2019 by the authors. Licensee MDPI, Basel, Switzerland. This article is an open access article distributed under the terms and conditions of the Creative Commons Attribution (CC BY) license (http://creativecommons.org/licenses/by/4.0/). 